\title{
Prophylaxis with intrathecal or high-dose methotrexate in diffuse large B-cell lymphoma and high risk of CNS relapse
}

\author{
Sabela Bobillo ${ }^{1,2,3}$, Erel Joffe (iD ${ }^{1}$, David Sermer ${ }^{1}$, Patrizia Mondello (iD) ${ }^{1}$, Paola Ghione ${ }^{1}$, Philip C. Caron ${ }^{1}$, Audrey Hamilton ${ }^{1}$, \\ Paul A. Hamlin 1,4 , Steven M. Horwitz ${ }^{1,4}$, Anita Kumar ${ }^{1,4}$, Matthew J. Matasar ${ }^{1,4}$, Connie L. Batlevi (iD ${ }^{1,4}$, Alison Moskowitz ${ }^{1,4}$, \\ Ariela Noy (DD ${ }^{1,4}$, Collette N. Owens ${ }^{1}$, M. Lia Palomba (D) ${ }^{1,4}$, David Straus ${ }^{1,4}$, Gottfried von Keudell ${ }^{1,4}$, Ahmet Dogan (ID ${ }^{5}$, \\ Andrew D. Zelenetz ${ }^{1,4}$, Venkatraman E. Seshan (D) ${ }^{6}$ and Anas Younes (iD) ${ }^{1,4}$
}

(c) The Author(s) 2021

\begin{abstract}
Although methotrexate (MTX) is the most widely used therapy for central nervous system (CNS) prophylaxis in patients with diffuse large B-cell lymphoma (DLBCL), the optimal regimen remains unclear. We examined the efficacy of different prophylactic regimens in 585 patients with newly diagnosed DLBCL and high-risk for CNS relapse, treated with rituximab, cyclophosphamide, doxorubicin, vincristine, and prednisone (R-CHOP) or R-CHOP-like regimens from 2001 to 2017, of whom 295 (50\%) received prophylaxis. Intrathecal (IT) MTX was given to 253 (86\%) and high-dose MTX (HD-MTX) to 42 (14\%). After a median follow-up of 6.8 years, 36 of 585 patients relapsed in the CNS, of whom 14 had received prophylaxis. The CNS relapse risk at 1 year was lower for patients who received prophylaxis than patients who did not: $2 \%$ vs. $7.1 \%$. However, the difference became less significant over time (5-year risk $5.6 \%$ vs. $7.5 \%$ ), indicating prophylaxis tended to delay CNS relapse rather than prevent it. Furthermore, the CNS relapse risk was similar in patients who received IT and HD-MTX (5-year risk 5.6\% vs. 5.2\%). Collectively, our data indicate the benefit of MTX for CNS prophylaxis is transient, highlighting the need for more effective prophylactic regimens. In addition, our results failed to demonstrate a clinical advantage for the HD-MTX regimen.
\end{abstract}

Blood Cancer Journal (2021)11:113; https://doi.org/10.1038/s41408-021-00506-3

\section{INTRODUCTION}

Diffuse large B-cell lymphoma (DLBCL) is the most common subtype of lymphoma accounting for $30-40 \%$ of all non-Hodgkin lymphomas. Central nervous system (CNS) relapse is an uncommon yet often fatal complication with a median overall survival (OS) of less than 6 months [1]. Overall, the incidence of CNS relapse in patients with DLBCL is around $2 \%$, which is lower than with other aggressive lymphomas, such as Burkitt lymphoma or acute lymphoblastic leukemia. However, the presence of certain risk factors might increase the risk of CNS relapse to 15\% [2].

Models have been made to identify patients with high risk of CNS relapse. The German High-Grade non-Hodgkin Lymphoma Study Group (DSHNHL) recently proposed a CNS prognostic model (CNSIPI) that includes five international prognostic index (IPI) factors and the involvement of kidney or adrenal glands. This model stratified DLBCL patients into three categories, low (0-1 risk factors), intermediate (2-3 risk factors), and high risk (4-6 risk factors) with a 2 -year rate of CNS relapse of $0.6 \%, 3.4 \%$, and $10.2 \%$, respectively [3]. However, involvement of certain extranodal sites, such as testes, breast, or bone marrow also confers an increased risk, even with low CNS-IPI [4-7]. In addition, the presence of MYC translocation together with $B C L 2$ translocation has been also associated with a higher risk of CNS relapse in several retrospective series $[8,9]$.
Finally, the combination of cell of origin (COO) determined by gene expression profiling (GEP) and CNS-IPI has recently improved the identification of DLBCL patients with high risk of CNS relapse, showing a 2-year CNS relapse rate up to $15 \%$ in patients with activated B-cell (ABC) phenotype and high CNS-IPI [10].

In high-risk patients, CNS prophylaxis is usually recommended, although the optimal regimen remains unclear. Some prospective and retrospective studies conducted in the rituximab era have demonstrated the lack of efficacy of intrathecal (IT) methotrexate (MTX) in patients treated with rituximab, cyclophosphamide, doxorubicin, vincristine, and prednisone (R-CHOP) or similar regimens [2, 10-13]. High-dose intravenous methotrexate (HDMTX) has been postulated as a possibly better option since the majority of relapses in the rituximab era occur in the brain parenchyma. However, different retrospective studies have shown conflicting results regarding its efficacy [14-19]. Finally, preliminary results from a multicenter retrospective study showed similar effectiveness of prophylactic HD-MTX and IT MTX in patients with aggressive non-Hodgkin lymphoma [20].

The purpose of this study was to evaluate the efficacy of different CNS prophylaxis regimens in preventing CNS relapse in DLBCL patients with risk factors for CNS recurrence who were treated with rituximab and chemotherapy in a single institution.

\footnotetext{
${ }^{1}$ Department of Medicine, Lymphoma Service, Memorial Sloan Kettering Cancer Center, New York, NY, USA. ${ }^{2}$ Department of Hematology, Vall d'Hebron Institute of Oncology (VHIO), Barcelona, Spain. ${ }^{3}$ Department of Medicine, Universitat Autonoma de Barcelona, Barcelona, Spain. ${ }^{4}$ Weill Cornell Department of Medicine, Weill Cornell Medical College, New York, NY, USA. ${ }^{5}$ Department of Pathology, Memorial Sloan Kettering Cancer Center, New York, NY, USA. ${ }^{6}$ Department of Epidemiology and Biostatistics, Memorial Sloan Kettering Cancer Center, New York, NY, USA. ${ }^{凶}$ email: anas.younes@astrazeneca.com
}

Received: 7 January 2021 Revised: 29 April 2021 Accepted: 10 May 2021

Published online: 16 June 2021 


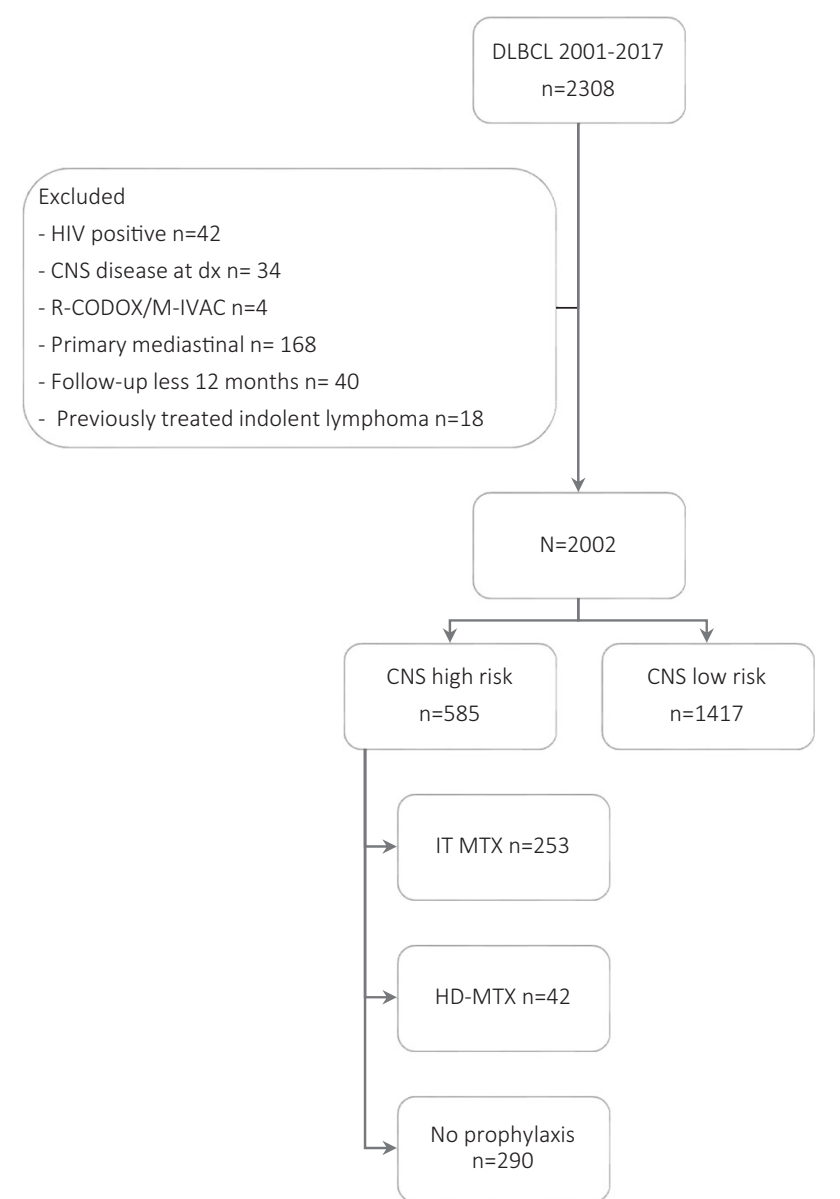

Fig. 1 Consort diagram. DLBCL diffuse large B cell lymphoma, CNS central nervous system, IT MTX intrathecal methotrexate, HD-MTX high-dose methotrexate.

\section{PATIENTS AND METHODS \\ Patients}

We retrospectively reviewed the records of all newly diagnosed patients with DLBCL at Memorial Sloan Kettering Cancer Center (MSKCC) from 2001 to 2017 , treated with frontline R-CHOP or R-CHOP-like regimens. In all cases, the pathology at diagnosis was confirmed by expert hematopathologists at MSKCC according to the World Health Organization classification of hematopoietic and lymphoid tumors. Patients with primary mediastinal B cell lymphoma, HIV positive or known CNS disease at diagnosis were excluded. Patients with history of indolent lymphoma previously treated with chemotherapy were also excluded. The Hans algorithm [21] was used to classify patients as germinal center B-cell like phenotype (GCB) or nongerminal center B-cell like (non-GCB). High risk for CNS relapse (HR-CNS) was defined by high-CNS-IPI (4-6 risk factors) or low or intermediate CNSIPI along with testicular, breast, kidney, adrenal glands, and/or bone marrow involvement. Patients with $M Y C$ and $B C L 2$ rearrangement were also included in HR-CNS group. Patients with low or intermediate CNS-IPI and paraspinal masses, sinus, orbit or skull involvement were not considered HR-CNS.

CNS prophylaxis was administered based on physician's preference. CNS relapse was diagnosed by the presence of radiological findings, detection of lymphoma cells in the CSF and/or by brain biopsy. This study was approved by the institutional reviewed board at MSKCC.

\section{Statistical analysis}

Competing risk analysis was used to analyze time to CNS relapse, with systemic non-CNS relapse and death without relapse as competing events. Time to event was calculated from the date of diagnosis to the date of one of the three events, relapse in the CNS, systemic relapse, or death without relapse whichever occurs first. OS from relapse was defined as the time from relapse until death of any cause. Patients' characteristics were compared using Fisher exact test for categorical variables and Kruskal-Wallis test for continuous variables. Kaplan-Meier analysis was implemented to report survival estimates across patients and logrank test to compare groups. We applied a non-parametric analysis of competing risks and used Gray's test to compare the cumulative incidence of CNS relapse between the different groups, with death and systemic relapse as competing events. Confidence intervals for risk ratio (RR) (ratio of cumulative incidence rate at fixed time-points) were obtained using bootstrap resampling. All statistical analyses were performed in R v3.6.

\section{RESULTS}

\section{Patient characteristics}

We identified 2308 patients treated with R-CHOP or R-CHOP-like regimens from 2001 to 2017 at MSKCC. We excluded 306 patients for the following reasons: HIV positive, $n=42$, CNS disease at diagnosis, $n=34$; primary mediastinal lymphoma, $n=168$; previously treated indolent lymphoma, $n=18$; treatment with $\mathrm{R}$ CODOX/M-IVAC, $n=4$ and follow-up shorter than 12 months, $n=$ 40. Finally, 2002 patients were considered and 585 (29\%) were classified as HR-CNS relapse and were included in the study (Fig. 1).

Median age was 68 years (range 21-91) and 301 (51\%) patients were male. The high-risk extranodal sites were: $\mathrm{BM}, n=118(20 \%)$, kidney/adrenal, $n=106$ (18\%); testes, $n=51$ (9\%) and breast, $n=$ $47(8 \%)$. One hundred and fifty-eight patients (27\%) had more than two extranodal sites involved. By CNS-IPI, patients were classified as low, 10\%; intermediate, 22\%; and high risk, $68 \%$. Eighteen (7\%) patients had MYC and BCL2 rearrangements. COO determined by Hans algorithm [21] was non-germinal center (nonGCB) in 229 (39\%) patients, germinal center (GCB) in $234(40 \%)$ patients and missing in 122 (21\%).

\section{CNS prophylaxis}

Two hundred and ninety (50\%) patients received at least one administration of CNS prophylaxis: IT MTX and/or cytarabine, $n=$ $253(87 \%)$; or HD-MTX, $n=42$ (13\%). Among the 42 patients who received HD-MTX, 11 received concomitant IT prophylaxis. Patients' characteristics by prophylactic regimen are shown in Table 1. Patients who received prophylaxis (IT or HD-MTX) were younger $(p<0.001)$ and presented with a better performance status $(E C O G<2)(p=0.002)$ compared with patients who did not receive prophylaxis. Patients with two or more extranodal sites involvement were more likely to receive CNS prophylaxis $(p<$ 0.001).

The median administrations of IT prophylaxis were 4 (range 1-9), and the majority of patients received MTX alone. The dose of IT MTX and IT cytarabine was 12 and $70 \mathrm{mg}$, respectively. Patients had a median of two cycles of HD-MTX (range 1-6), at a median dose of $3500 \mathrm{mg} / \mathrm{m}^{2}$ (range $2000-3500 \mathrm{mg} / \mathrm{m}^{2}$ ). Overall, 23 patients (55\%) had HD-MTX at the end of R-CHOP-like treatment and 19 (45\%) patients during R-CHOP-like treatment. Patients receiving HD-MTX were admitted to the hospital and received leucovorin rescue starting $24 \mathrm{~h}$ after MTX. Overall, 6 out of 42 patients (14\%) developed acute renal injury (grade 3 in all cases) related to HD-MTX; two patients at the end of chemotherapy treatment and four during systemic chemotherapy treatment. All patients recovered completely and no patient required dialysis. None of the patients received further HD-MTX after developing renal injury, two patients transitioned to IT MTX, one patient received a single administration of high-dose cytarabine, and three patients did not receive further prophylactic treatment.

\section{CNS relapse and the effect of prophylaxis on CNS relapse} After a median follow-up of 6.8 years, 36 out of 585 patients considered HR-CNS, relapsed in the CNS with a 5 -year risk of $6.5 \%$. Fourteen (39\%) patients had received prophylaxis: 12 IT and 2 HDMTX. The risk of CNS relapse at 5 years for patients who received 
Table 1. Patient's characteristics.

\begin{tabular}{|c|c|c|c|c|}
\hline Variables & $\begin{array}{l}\text { IT methotrexate } \\
\text { n (\%) }\end{array}$ & $\begin{array}{l}\text { HD-methotrexate } \\
n(\%)\end{array}$ & $\begin{array}{l}\text { No prophylaxis } \\
n(\%)\end{array}$ & $p$ value \\
\hline Median age (range) & $64(21-86)$ & $63(27-81)$ & $72(24-91)$ & $<0.001$ \\
\hline \multicolumn{5}{|l|}{ ECOG } \\
\hline $0-1$ & $160(63)$ & $27(64)$ & $142(49)$ & 0.002 \\
\hline I-II & $30(12)$ & $4(10)$ & $30(10)$ & 0.81 \\
\hline III-IV & $223(88)$ & $38(90)$ & $260(90)$ & \\
\hline \multicolumn{5}{|l|}{ Serum LDH } \\
\hline Above normal & $198(78)$ & $28(67)$ & $207(71)$ & 0.14 \\
\hline Missing & $5(2)$ & 0 & $17(6)$ & \\
\hline \multicolumn{5}{|l|}{ CNS-IPI risk $^{\mathrm{a}}$} \\
\hline 2 & $28(11)$ & $4(10)$ & $17(6)$ & \\
\hline 3 & $41(16)$ & $4(9)$ & $31(11)$ & \\
\hline 4 & $107(43)$ & $16(38)$ & $157(54)$ & \\
\hline 5 & 41 (16) & $12(29)$ & 49 (17) & \\
\hline 6 & $10(4)$ & $1(2)$ & $6(2)$ & \\
\hline \multicolumn{5}{|l|}{ CNS-IPI risk groups ${ }^{a}$} \\
\hline Low 0-1 & $26(10)$ & $5(12)$ & $30(10)$ & 0.009 \\
\hline Intermediate $2-3$ & $69(27)$ & $8(19)$ & $48(17)$ & \\
\hline High 4-6 & $158(63)$ & $29(69)$ & $212(73)$ & \\
\hline \multicolumn{5}{|l|}{ High risk site } \\
\hline Double-hit & $18(7)$ & $5(12)$ & $11(4)$ & 0.05 \\
\hline \multicolumn{5}{|l|}{ Treatment } \\
\hline $\mathrm{R}-\mathrm{CHOP}$ & $143(57)$ & $32(76)$ & $220(76)$ & $<0.001$ \\
\hline $\mathrm{R}-\mathrm{EPOCH}$ & $43(17)$ & $7(17)$ & $40(14)$ & \\
\hline R-CHOP/RICE & $67(26)$ & $3(7)$ & $30(10)$ & \\
\hline \multicolumn{5}{|l|}{ Cell of origin } \\
\hline Germinal center & $104(41)$ & $14(33)$ & $116(40)$ & 0.15 \\
\hline Non-germinal center & $104(41)$ & $23(55)$ & $102(35)$ & \\
\hline Missing & 45 (18) & $5(12)$ & $72(25)$ & \\
\hline
\end{tabular}

IT intrathecal, MTX methotrexate, HD high-dose, ECOG Eastern Cooperative Oncology Group, LDH lactate dehydrogenase, CNS-IPI central nervous system international prognostic index, $R$-CHOP rituximab, cyclophosphamide, doxorubicin, vincristine, prednisone, $R$-EPOCH rituximab, etoposide, cyclophosphamide, doxorubicin, vincristine, prednisone, RICE rituximab, ifosfamide, carboplatin, etoposide.

ancludes patients who were missing baseline LDH but were grouped regardless of its value.

IT, HD-MTX, or no prophylaxis was $5.5 \% ; 5 \%$ and $7.5 \%(p=0.34)$, respectively (Fig. 2). The risk of CNS relapse by prophylaxis was similar when excluding patients who received concomitant HDMTX and IT (Supplementary Fig. 1). CNS relapse risk was similar among patients who received $\mathrm{R}-\mathrm{CHOP}, \mathrm{R}-\mathrm{EPOCH}$, and $\mathrm{R}-\mathrm{CHOP} /$ RICE ( $p=0.12)$ (Supplementary Fig. 2). The 5-year CNS relapse risk for patients considered low-risk CNS and not included in the study was $1.1 \%$.
The median time to relapse since first diagnosis was 9 months (range 6-110 months). Patients who received prophylaxis, either IT or HD-MTX, relapsed later than patients who did not receive prophylaxis, with a median time to relapse of 19 months (range 7-55 months) vs. 8 months (range 6-110 months), respectively. The risk of relapse at 1 year was lower for patients who received prophylaxis compared to patients who did not receive prophylaxis $2 \%$ vs. $7.1 \%$, RR 0.29 (95\% Cl; 0.08,0.66). However, over time, the 


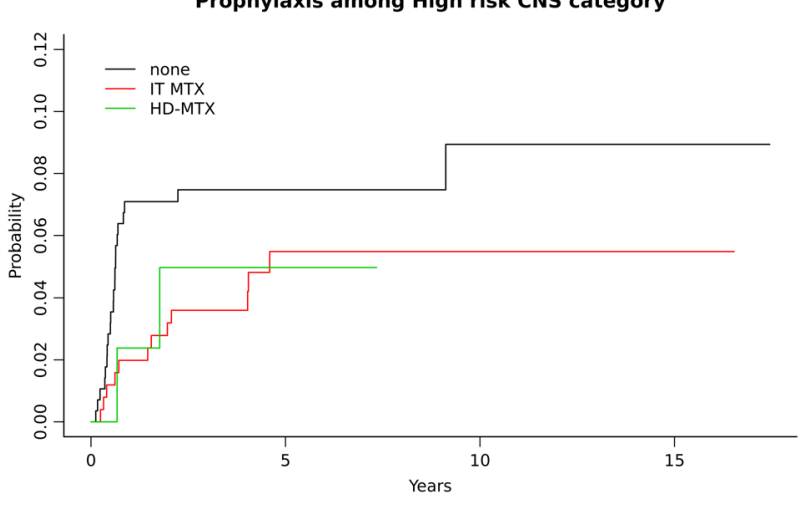

Fig. 2 Cumulative incidence of CNS relapse rate by prophylactic strategy. IT MTX intrathecal methotrexate, HD-MTX high-dose methotrexate.

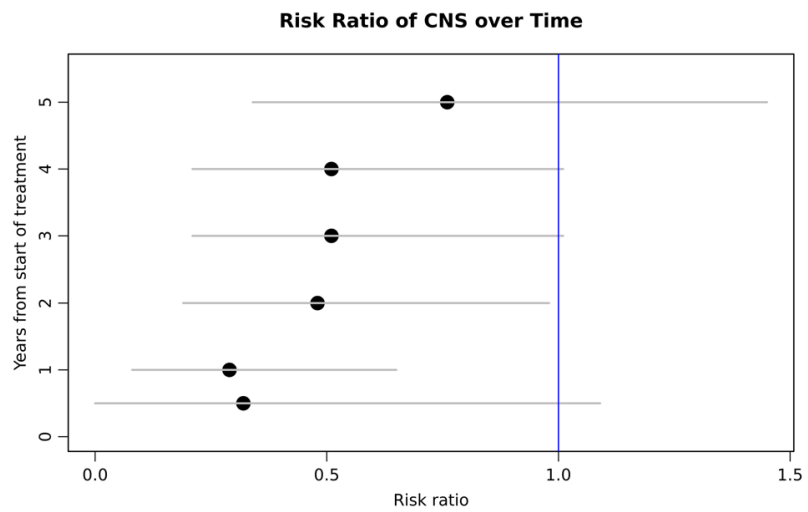

Fig. 3 Risk ratio of CNS relapse with and without prophylaxis over time.

risk of CNS relapse became closer among prophylaxis and noprophylaxis groups, with a 3-year risk of $3.8 \%$ vs. $7.5 \%$ (RR $0.51, \mathrm{Cl}$ $95 \% ; 0.22,1.04$ ) and a 5 -year risk of $5.6 \%$ vs. $7.5 \%$ (RR 0.76, Cl 95\%; $0.35,1.50)$, respectively (Fig. 3 ).

At the time of CNS relapse, $26(72 \%)$ patients presented with disease confined to the CNS and 10 (28\%) patients had a concomitant systemic and CNS relapse. The brain parenchyma was the most common site of relapse $(47 \%)$, followed by leptomeninges (30\%) and both sites (23\%). Sites of relapse by prophylactic treatment are detailed in Table 2.

Patients with CNS relapse $(n=36)$ presented worse outcomes than patients with systemic relapse without CNS involvement $(n=145)$ with a median OS of 4.9 months vs. 17.1 months, respectively ( $p=0.003$ ) (Fig. 4).

The COO determined by the Hans algorithm was available in 463 out of 585 patients, of whom 229 (49\%) had a non-GCB phenotype and 234 (51\%) patients had a GCB phenotype. Overall, $127(55 \%)$ patients in the non-GCB group and $108(46 \%)$ in the GCB group received prophylaxis. Patients with non-GCB phenotype had a higher risk of CNS relapse compared with patients with GCB subtype with a 5 -year risk of $9.9 \%$ vs. $4.5 \%$, respectively $(p=0.03)$ (Fig. 5).

Finally, we performed a sub-analysis excluding patients with low or intermediate CNS-IPI and bone marrow involvement $(n=$ 66), since the association between bone marrow and CNS relapse is controversial. We observed a 5 -year CNS relapse risk of $5.2 \%$, $5.3 \%$, and $7.5 \%$ for patients receiving IT and HD-MTX and no prophylaxis; respectively. Due to the low number of events in this group, we could not perform a sub-analysis to investigate the risk of CNS relapse in patients with bone marrow involvement.
Table 2. Site of CNS relapse by CNS prophylaxis.

\begin{tabular}{llll} 
& \multicolumn{2}{l}{ Site of CNS relapse } & \\
$\begin{array}{l}\text { CNS prophylaxis } \\
\text { regimen }\end{array}$ & Leptomeninges & Parenchyma & Both \\
IT & $5(42 \%)$ & $3(25 \%)$ & $4(33 \%)$ \\
\hline HD-MTX & $1(50 \%)$ & $1(50 \%)$ & - \\
\hline No prophylaxis & $5(23 \%)$ & $13(57 \%)$ & $4(18 \%)$ \\
\hline
\end{tabular}

CNS central nervous system, IT intrathecal, MTX methotrexate, HD highdose.

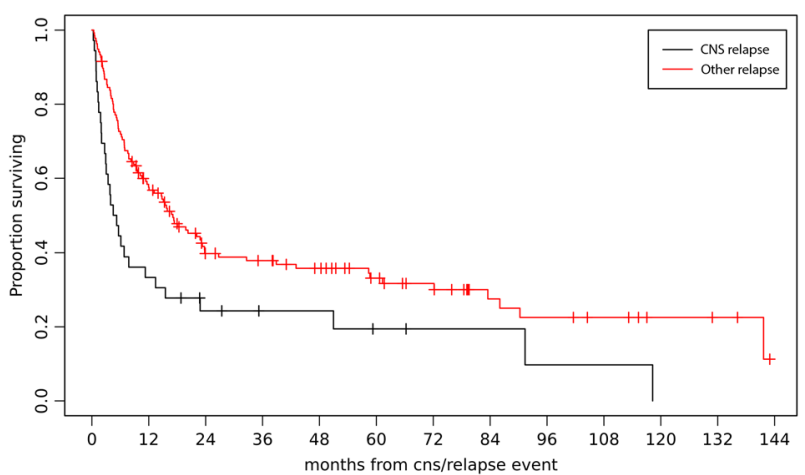

Fig. 4 Overall survival of patients with CNS relapse vs. other relapse.

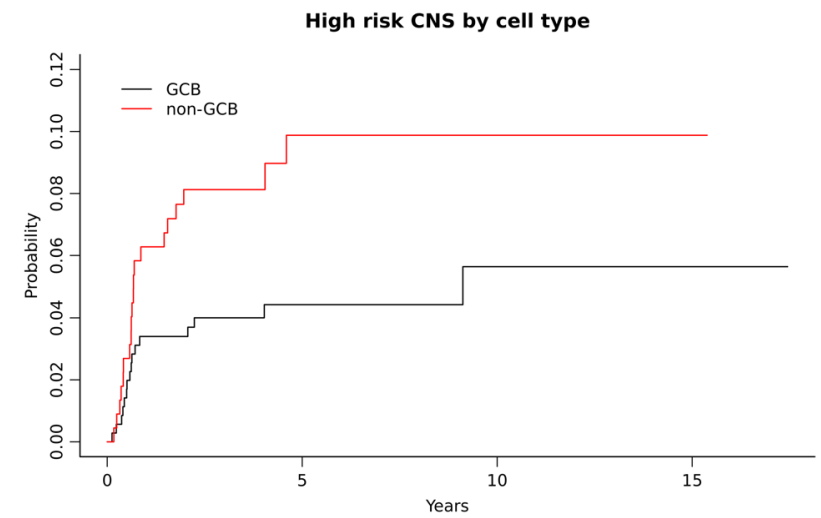

Fig. 5 Cumulative incidence of CNS relapse by cell of origin. GCB germinal center B-cell phenotype, non-GCB non germinal center Bcell phenotype.

\section{DISCUSSION}

To our knowledge, this is one of the largest series analyzing the role of CNS prophylaxis exclusively in patients with high risk of CNS relapse in the modern era. According to the CNS-IPI model, we considered high-risk for CNS relapse patients with 4 to 6 risk factors. In addition, we included patients with involvement of certain extranodal sites traditionally associated with an increased risk of CNS relapse, such as testes, breast, kidney, and bone marrow [3-6], regardless the CNS-IPI; making our results more informative. We also included double-hit lymphomas that have been associated with a high risk of CNS relapse, although estimates vary widely among different studies $[2,8,9]$. Notably, $50 \%$ of the patients included in our study did not receive CNS prophylaxis. These patients tended to be older and had worse performance status than those who receive prophylaxis. Similar results were found in recent large retrospective studies [13, 19].

Consistent with recently published studies in the rituximab era, we observed a risk of CNS relapse of $6.5 \%$ at 5 years in the HR-CNS 
group $[13,15,20,22,23]$. Furthermore, our results are similar to a recent real-world study from Sweden including 4205 patients with $\mathrm{DLBCL}$, that reported a 2-year CNS risk of $8 \%$ in the high-risk patients [23]. Other investigators reported a slightly higher incidence of CNS relapse, with a 2-year risk of $10.2 \%$ [10]. The lower incidence of our study is likely due to the fact that we frequently perform brain magnetic resonance imaging in addition to a diagnostic lumbar puncture. Therefore, patients with active CNS involvement at diagnosis are promptly identified and excluded from the prophylactic strategy.

Whether CNS prophylaxis is useful in preventing CNS relapse has been addressed in several studies over the past years, including the most widely used strategy IT MTX and more recently intravenous methotrexate. The majority of the retrospective studies and post hoc analysis from prospective trials showed the lack of efficacy of IT prophylaxis in the rituximab era [10-13, 22]. In this regard, Kumar et al. using the prospectively collected National Comprehensive Cancer Network database, analyzed the risk of CNS relapse in 989 newly diagnosed DLBCL, $117(11.8 \%)$ of whom had received prophylaxis, mostly IT MTX. They described no benefit from prophylaxis in the whole population and also in high-risk patients, though patients with involvement of kidney or adrenal glands or patients with double-hit lymphomas were not included in the highrisk group [22]. More recently, a large retrospective study including 690 patients older than 70 years of whom 271 had high-risk CNS-IPI, also described a similar rate of CNS relapse regardless the use of IT MTX prophylaxis [HR $1.34(95 \% \mathrm{Cl}, 0.46-3.86)]$ [13]. Our series included only high-risk patients from all ages who received mostly IT MTX as prophylaxis (43\%). In line with previously reported, we did not observe a clear benefit from IT MTX on preventing CNS relapse, especially after the first year of immunochemotherapy.

In recent years, the use of HD-MTX administrated mid chemotherapy cycles or after completing systemic chemotherapy was proposed as an alternative strategy to prevent CNS recurrence. The rational is based on the observation that CNS relapses frequently involve the brain parenchyma [14-16]. This approach was initially evaluated in the pre-rituximab era by the Groupe d'Etudes des Lymphomes de l'Adulte/Lymphoma Study Association comparing high-dose chemotherapy plus two cycles of HDMTX vs. CHOP without CNS prophylaxis, with significant reduction in the CNS relapse risk of $0.8 \%$ vs. $2.7 \%$, respectively [24]. In the modern era, different retrospective series had supported this evidence in patients treated with R-CHOP chemotherapy [14-16], although two recent retrospective studies have shown no clear benefit $[17,18]$. More recently, preliminary results from a large retrospective series from Canada including 326 high-risk DLBCL patients, showed the lack of effectiveness of HD-MTX with a CNS relapse risk of $11.2 \%$ for patients who received HD-MTX $(n=115)$ vs. $12.2 \%$ for patients who did not [19]. Consistent with these studies, our data also failed to demonstrate a clinical advantage for using the more toxic intravenous HD-MTX regimen. More recently, a multicenter retrospective study found no difference in the efficacy between intravenous HD-MTX and IT MTX prophylaxis, with a CNS relapse risk of $5 \%$ vs. $7 \%$, respectively [20].

A multicenter retrospective Australian study analyzed 217 highrisk patients treated with: (1) R-CHOP plus IT MTX, (2) R-CHOP pus HD-MTX, or (3) dose-intensive chemotherapy plus HD-MTX. They observed a lower incidence of CNS relapse in patients receiving HD-MTX compared to IT MTX, with a 3-year CNS relapse rate of $18.4 \%$ vs. $6.9 \%$ vs. $2.3 \%$, for groups 1,2 , and 3 , respectively [16]. Notably, in this study, only $37 \%$ of patients from the IT MTX group had received rituximab as part of the induction therapy, while nearly all patients in the HD-MTX group received immunochemotherapy [16]. In our study where all patients had received immunochemotherapy, we did not detect differences in the efficacy between IT and HD-MTX, although the number of patients in the HD-MTX group was low.
Although in our series the risk of CNS relapse was similar regardless the use of prophylaxis, we found that within the first year from diagnosis the risk was higher in patients who did not receive prophylaxis compared to patients who received IT or HDMTX with a risk of $7.1 \%$ vs. $2 \%$ vs. $2.4 \%$, respectively. However, over time, the risk became similar between groups, raising up to $5.6 \%$ and $5.2 \%$ at 5 years in the HD-MTX and IT groups, respectively. These findings were not observed in previous studies analyzing the role of CNS prophylaxis [13, 22]. However, the median follow-up in these studies was around 2.5 years, so late relapses might have been underestimated. Our evidence suggests CNS prophylaxis might help to partially control undetected CNS disease present at diagnosis delaying the occurrence of CNS relapse, rather than preventing it. Furthermore, the use of CNS prophylaxis might not prevent from late CNS relapse in the HRCNS population.

Finally, we noticed that the presence of non-GCB phenotype determined by immunohistochemistry confers an increased risk of CNS relapse in the HR-CNS population. These results are in accordance with a recent publication analyzing the impact of $\mathrm{COO}$ by GEP in 1418 patients from the GOYA phase 3 trial. In this study, the authors found that $A B C$ or unclassified phenotype was an independent risk factor for CNS relapse, and patients with highCNS-IPI together with an $A B C$ phenotype had a 2-year CNS relapse rate of $15 \%$ [10]. Interestingly, although we used immunohistochemistry techniques to determine the COO phenotype, we observed similar results, suggesting that in the absence of molecular analysis, $\mathrm{COO}$ assessed by immunohistochemistry along with other risk factors could be useful to identify high-risk patients.

In conclusion, our study highlights the need for developing more effective CNS prophylaxis regimens than MTX. Furthermore, our data in addition to emerging data from other centers, did not demonstrate clinical advantage for using intravenous HD-MTX over traditional IT MTX. Since HD-MTX is associated with higher incidence of adverse events resulting in more delays in the administration of R-CHOP cycles, we recommend that benefit/risk assessment should be carefully considered before adopting HDMTX for CNS prophylaxis.

\section{REFERENCES}

1. El-Galaly TC, Cheah CY, Bendtsen MD, Nowakowski GS, Kansara R, Savage KJ, et al Treatment strategies, outcomes and prognostic factors in 291 patients with secondary CNS involvement by diffuse large B-cell lymphoma. Eur J Cancer. 2018:93:57-68.

2. Gleeson M, Counsell N, Cunningham D, Chadwick N, Lawrie A, Hawkes EA, et al. Central nervous system relapse of diffuse large B-cell lymphoma in the rituximab era: results of the UK NCRI R-CHOP-14 versus 21 trial. Ann Oncol. 2017;28:2511-6.

3. Schmitz N, Zeynalova S, Nickelsen M, Kansara R, Villa D, Sehn LH, et al. CNS international prognostic index: a risk model for CNS relapse in patients with diffuse large B-cell lymphoma treated with R-CHOP. J Clin Oncol. 2016;34:3150-6.

4. Vitolo U, Chiappella A, Ferreri AJ, Martelli M, Baldi I, Balzarotti M, et al. First-line treatment for primary testicular diffuse large B-cell lymphoma with rituximabCHOP, CNS prophylaxis, and contralateral testis irradiation: final results of an international phase II trial. J Clin Oncol. 2011;29:2766-72.

5. Hu S, Song Y, Sun X, Su L, Zhang W, Jia J, et al. Primary breast diffuse large B-cell lymphoma in the rituximab era: Therapeutic strategies and patterns of failure. Cancer Sci. 2018;109:3943-52.

6. Hosein PJ, Maragulia JC, Salzberg MP, Press OW, Habermann TM, Vose JM, et al. A multicentre study of primary breast diffuse large B-cell lymphoma in the rituximab era. Br J Haematol. 2014;165:358-63.

7. Kridel R, Telio D, Villa D, Sehn LH, Gerrie AS, Shenkier T, et al. Diffuse large B-cell lymphoma with testicular involvement: outcome and risk of CNS relapse in the rituximab era. Br J Haematol. 2017;176:210-21.

8. Oki Y, Noorani M, Lin P, Davis RE, Neelapu SS, Ma L, et al. Double hit lymphoma: the MD Anderson Cancer Center clinical experience. Br J Haematol. 2014;166:891-901.

9. Petrich AM, Gandhi M, Jovanovic B, Castillo JJ, Rajguru S, Yang DT, et al. Impact of induction regimen and stem cell transplantation on outcomes in double-hit lymphoma: a multicenter retrospective analysis. Blood. 2014;124:2354-61. 
10. Klanova M, Sehn LH, Bence-Bruckler I, Cavallo F, Jin J, Martelli M, et al. Integration of cell of origin into the clinical CNS International Prognostic Index improves CNS relapse prediction in DLBCL. Blood. 2019;133:919-26.

11. Boehme V, Schmitz N, Zeynalova S, Loeffler M, Pfreundschuh M. CNS events in elderly patients with aggressive lymphoma treated with modern chemotherapy (CHOP-14) with or without rituximab: an analysis of patients treated in the RICOVER-60 trial of the German High-Grade Non-Hodgkin Lymphoma Study Group (DSHNHL). Blood. 2009;113:3896-902.

12. Schmitz N, Zeynalova S, Glass B, Kaiser U, Cavallin-Stahl E, Wolf M, et al. CNS disease in younger patients with aggressive B-cell lymphoma: an analysis of patients treated on the Mabthera International Trial and trials of the German High-Grade Non-Hodgkin Lymphoma Study Group. Ann Oncol. 2012;23:1267-73.

13. Eyre TA, Kirkwood AA, Wolf J, Hildyard C, Mercer C, Plaschkes H. et al. Stand-alone intrathecal central nervous system (CNS) prophylaxis provide unclear benefit in reducing CNS relapse risk in elderly DLBCL patients treated with $\mathrm{R}-\mathrm{CHOP}$ and is associated increased infection-related toxicity. Br J Haematol. 2019;187:185-94.

14. Abramson JS, Hellmann M, Barnes JA, Hammerman $P$, Toomey $C$, Takvorian $T$, et al. Intravenous methotrexate as central nervous system (CNS) prophylaxis is associated with a low risk of CNS recurrence in high-risk patients with diffuse large B-cell lymphoma. Cancer. 2010;116:4283-90.

15. Ferreri AJ, Bruno-Ventre $M$, Donadoni G, Ponzoni M, Citterio G, Foppoli $M$, et al. Risk-tailored CNS prophylaxis in a mono-institutional series of 200 patients with diffuse large B-cell lymphoma treated in the rituximab era. $\mathrm{Br} J$ Haematol. 2015;168:654-62.

16. Cheah CY, Herbert KE, O'Rourke K, Kennedy GA, George A, Fedele PL, et al. A multicentre retrospective comparison of central nervous system prophylaxis strategies among patients with high-risk diffuse large B-cell lymphoma. $\mathrm{Br} J$ Cancer. 2014;111:1072-9.

17. Lee K, Yoon DH, Hong JY, Kim S, Lee K, Kang EH, et al. Systemic HD-MTX for CNS prophylaxis in high-risk DLBCL patients: a prospectively collected, single-center cohort analysis. Int J Hematol. 2019;110:86-94.

18. Goldschmidt N, Horowitz NA, Heffes V, Darawshy F, Mashiach T, Shaulov A, et al. Addition of high-dose methotrexate to standard treatment for patients with high-risk diffuse large B-cell lymphoma contributes to improved freedom from progression and survival but does not prevent central nervous system relapse. Leuk Lymphoma. 2019;60:1890-8.

19. Puckrin R, Darsa EIH, Ghosh S, Peters A, Stewart DA. Lack of effectiveness of intravenous high-dose methotrexate for prevention of CNS relapse in patients with high-risk DLBCL: a retrospective analysis from Alberta, Canada. Blood. 2020;136(supplem 1):26-7.

20. Orellana-Noia VM, Reed DR, Sen JM, Barlow C, Malecek MK, Kahl BS, et al. CNS prophylaxis during front-line therapy in aggressive non-Hodgkin lymphomas: real-world outcomes and practice patterns from 19 US academic institutions. Blood. 2020;136(supplem 1):27-8.

21. Hans CP, Weisenburger DD, Greiner TC, Gascoyne RD, Delabie J, Ott G, et al. Confirmation of the molecular classification of diffuse large B-cell lymphoma by immunohistochemistry using a tissue microarray. Blood. 2004;103:275-82.

22. Kumar A, Vanderplas A, LaCasce AS, Rodriguez MA, Crosby AL, Lepisto E, et al. Lack of benefit of central nervous system prophylaxis for diffuse large B-cell lymphoma in the rituximab era: findings from a large national database. Cancer. 2012;118:2944-51.

23. Harrysson S, Eloranta S, Ekberg S, Enblad G, Jerkeman M, Wahlin BE, et al. Incidence of relapsed/refractory diffuse large B-cell lymphoma (DLBCL) including CNS relapse in a population-based cohort of 4243 patients in Sweden. Blood Cancer J. 2021;11:9.

24. Tilly $H$, Lepage $E$, Coiffier B, Blanc M, Herbrecht R, Bosly A, et al. Intensive conventional chemotherapy (ACVBP regimen) compared with standard CHOP for poor-prognosis aggressive non-Hodgkin lymphoma. Blood. 2003;102:4284-9.

\section{ACKNOWLEDGEMENTS}

This work was supported in part by research funding from Fundación Alfonso Martín Escudero to SB. Data from this manuscript were presented at the 61st Annual Meeting of the American Society of Hematology, Orlando, FL, December 7th-10th, 2019.

\section{AUTHOR CONTRIBUTIONS}

SB and AY conceived the project, analyzed the data, and wrote the manuscript. VS analyze the data, wrote the manuscript and provide the figures. DS contributed to analyze the data. CLB, PCC, AH, PAH, SMH, AK, MJM, AM, AN, DS, PG, PM, CNO, MLP, $D S, G K, A D Z$, and $A D$ treated patients and approved the manuscript.

\section{COMPETING INTERESTS}

$A D$ has received personal fees from Roche, Corvus Pharmaceuticals, Physicians' Education Resource, Seattle Genetics, Peerview Institute, Oncology Specialty Group, Pharmacyclics, Celgene, Novartis, Takeda and research grants from National Cancer Institute and Roche. CLB has received grant funding from Janssen, Novartis, Epizyme, Xynomics, Bayer, BMS, and served as a consultant for Life Sci, GLG, Celgene, Seattle Genetics, Xynomics, and holds honorarium from Dava Oncology. $\mathrm{PH}$ receives research support from Portola, Novartis/GSK, Molecular Templates, Janssen Pharmaceuticals, and served as consultant for Karyopharm, Juno, Portola, Celgene, AstraZeneca. SH has received research funding from ADCT therapeutics, Aileron, Forty-Seven, Verastem, Kyowa Hakko Kirin, Millennium Pharmaceuticals Inc, Celgene, Trillium, Daiichii Sankyo, and consults for Astex, Affimed, Merck Sharp and Dome, Kyowa Hakko Kirin Pharma, Corvus Pharmaceuticals Inc, Celgene, Portola Pharmaceuticals, Takeda Millennium, Innate Pharma, Verastem, Miragen Therapeutics Inc, Seattle Genetics, ADCT. AK receives research funding from Abbvie Pharmaceuticals, Adaptive Biotechnologies, Pharmacyclics, Seattle Genetics, and serves on advisory board for Celgene and AstraZeneca. MLP receives honoraria from Flagship Ventures, Novartis, Evelo, Seres Therapeutics, Jazz Pharmaceuticals, Therakos, Amgen, Merk and consults for Merk and Pharmacyclics. AN receives honoraria from Janssen, Pharmacyclics, Prime Oncology, and consults for Medscape, and serves on advisory board for Janssen, and serves on the speakers' bureau for Prime Oncology, and receives research funding for Rafael Pharma and Pharmacyclics. AM receives research support from Seattle Genetics, Merck, Bristol-Myers Squibb, Incyte, and receives honorarium from Kyowa Hakko Kirin Pharma, Miragen Therapeutics, Takeda Pharmaceuticals, ADC Therapeutics, Seattle Genetics, Cell Medica, Bristol-Myers Squibb, Erytech Pharma. DS consults for InPractice Elselvier, Seattle Genetics, and is on speaker's bureau for Medical Crossfire. ADZ consults for Genentech/Roche, Gilead, Celgene, Janssen, Amgen, Novartis, Adaptive Biotechnology, Verastem, and serves on advisory board for MorphoSys, Gilead, Genentech, Abbvie, AstraZeneca, Pharmacyclics, and receives research funding from MEl Pharmaceuticals, Roche, Gilead, Beigene. AY received research support from Janssen, Curis, Merck, BMS, Syndax, Roche, and honorarium from Janssen, Abbvie, Merck, Curis, Epizyme, Roche, Takeda, and consulted for Biopath, Xynomics, Epizyme, Roche, Celgene, HCM. AY is currently an employee of AstraZeneca. The remaining authors declare no competing interests.

\section{ADDITIONAL INFORMATION}

Supplementary information The online version contains supplementary material available at https://doi.org/10.1038/s41408-021-00506-3.

Correspondence and requests for materials should be addressed to A.Y.

Reprints and permission information is available at http://www.nature.com/ reprints

Publisher's note Springer Nature remains neutral with regard to jurisdictional claims in published maps and institutional affiliations.

Open Access This article is licensed under a Creative Commons Attribution 4.0 International License, which permits use, sharing, adaptation, distribution and reproduction in any medium or format, as long as you give appropriate credit to the original author(s) and the source, provide a link to the Creative Commons license, and indicate if changes were made. The images or other third party material in this article are included in the article's Creative Commons license, unless indicated otherwise in a credit line to the material. If material is not included in the article's Creative Commons license and your intended use is not permitted by statutory regulation or exceeds the permitted use, you will need to obtain permission directly from the copyright holder. To view a copy of this license, visit http://creativecommons. org/licenses/by/4.0/.

(c) The Author(s) 2021 